\title{
Fréquence au Sénégal du botulisme animal d'origine hydrique
}

\author{
par M. P. DOUTRE
}

\begin{abstract}
RÉSUMÉ
L'auteur rapporte trois observations de botulisme anımal ayant pour origine l'absorption d'une eau d'abreuvement contamınée par des cadavres de petits mammıfères. Une hypothèse concernant l'orıgıne de l'ép।zootıe observée depuls 1959 dans le Ferlo est formulée.
\end{abstract}

Depuis moins d'un an, par trois fols, le diagnostic de botulisme a été posé à la suite de mortalités survenues chez des animaux d'espèces variées, abreuvés avec l'eau retırée de troıs puits différents.

La relation de ces trois observations fait l'abjet de la présente note :

\section{Observation $n^{0} 1$ :}

Elle a été rapportée dans une note publiée récemment (*). Des bovins et des chevaux, dont le nombre n'est pas précisé, succombent en offrant des signes paralytıques, après avorr absorbé l'eau du puits de Taiba-Thiékéné (département de $M^{\prime}$ Backé). Les commémoratifs précisent que des chats y ont été noyés.

L'ensemencement en boullon $\mathrm{V}$-F anaérobie de quelques sédıments, présents dans le fond de la bouteille ayant servi au transport d'un prélèvement d'eau, donne une culture mixte dont le surnageant se révèle contenır de la toxıne botulique (DMM/souris $=0,00005 \mathrm{ml}$ ).

La séroneutralisation effectuée sur souris montre qu'une souche de Clostridium botulinum de type $D$ est responsable de la mortalıté constatée.

(*) Rev. Elev, Méd. vét. Poys trop., 1969, 22, 1.

\section{Observation no 2 :}

Elle provient de la régın de Podor. Le 13 décembre 1968, au village de Gadde Boffé, 26 moutons, 6 ânes et 2 chevaux succombent après avolr absorbé l'eau d'un puits où également un chat avalt été précıpité. Des prèlèvements recueillis sur des animaux morts, le cadavre du chat et un échantillon d'ecu parviennent au Laboratoire.

De la toxine botulıque est mise en évidence dans le surnageant de la culture, en boullon $\checkmark$-F anaéroble, de fragments desséchés du cadavre du chat (DMM/souris $=0,00005 \mathrm{ml}$ ). La séroneutralisation montre qu'il s'agit cette fols du type $\mathrm{C}$ de $\mathrm{Cl}$. botulinum.

\section{Observation no 3 :}

Elle est effectuée au village de Beytil-Moukhadess situé à $80 \mathrm{~km}$ dans l'est de Khaffrine. Nous avons eu la possibilité de nous rendre sur les lieux de 9 janvier 1969.

118 bovins, 10 moutons ef 1 cheval ont succombé après avorr bu l'eau du puits autour duquel se rassemble une communauté familiale de quelques cases. A notre arrivée, le puits avalt été vidé et un cadarre d'écureuil fouisseur, appelé communément rat-palmiste (Xerus ery- 
thropus) y avait été découvert après environ 15 jours d'immersion.

Près des restes décomposés d'un bovin mort depuis une semaıne, un olsecu se traînait, incapable du moindre vol (Pie-grièche à bec jaune, Corvinella corvina).

Deux bovins sacrifiés à l'agonie ont fourni des prélèvements qui furent rapportés au Laboratoire, aınsı qu'un échantillon d'eau et la peau de l'écurevil.

La culture en milieu $V-F$ anaérobıe d'un broyat de fole et celle d'un broyat d'anse intestincle d'un des bovins abattus permettent d'obtenir un surnageant de centrifugation qui se montre contenir de la toxine botulique (DMM/ souris $0,005 \mathrm{ml}$ ). La séroneutralisation sur souris révèle que le type $C$ est de nouveau en cause.

L'origine botulique de l'intoxication apparaît comme évidente et l'hypothèse d'un empolsonnement, dô à la malveillance, par une substance chimıque étaıt désormaıs écartée. Une bouteille, type boutelle à sirop, avait été en effet sortıe du puits, le propriétaire avait porté plainte et une enquête débutait....

\section{DISCUSSION}

En six mois, trois cas d'intoxication botulique, ayant pour origine une eau d'abreuvement souillée par des cadavres de petits mammifères, ont été constatés par le Laboratoire. Cette répétition, rapprochée dans le temps, semble pour le molns étonnante, lorsque l'on sait que dans les années passées, jamals un seul exemple de ce genre ne fut rapporté par les agents du Service de l'Elevage.

Toutefois, ces accidents permettent de formuler une hypothèse quant à l'origine de l'éplzootie de botulisme rencontrée dans la région d'élevage du Ferlo depuis déjà près d'une décade (les premiers rapports remontent à 1959). Il est en effet possible de considérer que, dans un ou plusieurs forages, l'eau d'un abreuvorr souillée par un cadavre de chat ou de petit mammıfère queiconque, alt été la cause d'une intoxication botulıque limitée. Les restes des animaux morts, dissémınés dans un rayon de plusieurs centaines de mètres autour du point d'eau contamıné, auraıent été à l'origıne de la propagation des spores botuliques, leur absorption étant facilitée par l'ostéophagie présentée par des bovins en état d'aphosphorose saisonnier. La dissémınation des restes, des ossements des nouvelles victımes ef leur consommation par des animaux carencés auraient permis à la maladie de faire tache d'huile et de s'étendre progressivement ò toute la région d'élevage.

L'accident survenu à Beytıl-Moukhadess, village situé bien en dehors du Ferlo, pourrait donc, si les cadavres n'étaient pas détruits ou enfous selon les recommandations formulées, être à l'orıgıne d'une seconde flambée de botulisme dans une zone d'élevage jusqu'alors indemne.

\section{Institut d'Elevage et de Médecine Vétérinare des Pays Tropicoux, Marsons-Alfort. Laboratorre National de l'Elevage ef de Recherches Vétérinaires Dakar (Sénégal).}

\section{SUMMARY}

\section{Frecuency of anımal botulism from hydric origin in Senegal}

The author reports three cases of animal botulism caused by the absorption of water from wells contaminated by corpses of small mammals An hypothesis concerning the origin of the outbreak observed since 1959 in the Ferlo is expressed.

\section{RESUMEN}

\section{Frecuencia del botulismo animal de origen hidrica en Senegal}

El autor relata tres observaciones de botulismo animal debido a la absorción de agua de pozos contamınados por cadáveres de pequeños mamíferos. Una hipotes ss concerniendo el origen de la epizootia que se encuentra desde 1959 en Ferlo ha sido formulada. 


\section{BIBLIOGRAPHIE}

1. CALVET (H.), PICART (P.), DOUTRE (M. P.) et CHAMBRON (J.). - Aphosphorose ef botulisme au Sénégal. Rev. Elev. Méd. vét. Pays irop., 1965, 18 (3) : p. 249-282.

2. DOUTRE (M. P.) et CHAMBRON (J.). - Le botulisme des ruminants ef des équidés au Sénégal. Caractères de la souche isolée de Cl. botulinum et de sa toxine. Rev. Elev. Méd. vét. Pays trop., 1966, 19 (4) : p. 495-510.

3. DOUTRE (M. P.). - Le botulisme animal au Sénégal. Bull. Off. int. Epiz., 1967, 67 (11-12) : p. 1497-1515.

4. DOUTRE (M.P.). - Première observation de botulisme $C$ beta chez le porc au Sénégal. Rev. Elev. Méd. vét. Pays trop., 1967, 20 (2) : p. 351-353.

5. DOUTRE (M.P.). - Botulisme de type C chez une tourterelle (Streptopelio roseogrisea bornuensis) du Ferlo (Sénégal). Rev. Elev. Méd. vét. Poys trop., 1967, 20 (4) : p. 601-604.

6. MULLER (J.). - Botulisme équin et bovin au Danemark. Bull. Off. int. Epiz., 1963, 59 : P. $1379-1390$.

7. PIGOURY (L.), MICHEL (C.) ef CHABASSOL. - Rôle de l'eau dans l'étiologie du botulisme animal. Rev. Cps Santé Armées, 1962, 3 : p. 649.

8. PREVOT (A. R.), HUET (M.) et TARDIEUX (P.). - Etude de vingt-cinq foyers récents de botulisme animal. Bull. Acad, vét. de France, 1950, 23 : p. 481-487.

8. PREVOT (A. R.) et SILLIOC (R.). - Une énigme biologique : chat et botulisme. Ann. Inst. Pasteur, 1955, 89 : p. 354-357. 